\title{
Síndrome Plurimetabólica Expressa Como Xantomas Eruptivos: A Importância Da Dermatologia No Diagnóstico De Doenças Sistêmicas.
}

\author{
Coelho, G.; Rocha, P.L.; Weinert, L.S.; \\ Apresentador: Germano Scheer Coelho
}

\section{Resumo}

Introdução: Xantomas eruptivos podem ser definidos como lesões cutâneas originárias do acúmulo de lipídios no interior de macrófagos localizados na derme, sugerindo, muitas vezes, alterações dos triglicerídeos (TG) plasmáticos associados a outros distúrbios endocrinológicos, como diabetes mellitus (DM) descompensado. Descrição do caso: Paciente de 33 anos, sexo masculino, branco, sem patologias prévias, procurou atendimento médico apresentando como única queixa lesões cutâneas disseminadas pelo corpo há 6 meses. Ao exame clínico-dermatológico, foram evidenciadas lesões pápulo- nodulares, de coloração eritêmato-amarelada, indolor, ocorrendo em membros superiores, dorso e, mais intensamente, em nádegas. Destacou-se, também, pressão arterial (PA) de 154 x $96 \mathrm{mmHg}$, índice de massa corporal (IMC) de $40 \mathrm{~kg} / \mathrm{m}^{2}$ e circunferência abdominal de $104 \mathrm{~cm}$. Exames laboratoriais demonstravam TG $2.825 \mathrm{mg} / \mathrm{dL}$, colesterol total $548 \mathrm{mg} /$ $\mathrm{dL}$, colesterol HDL $30 \mathrm{mg} / \mathrm{dL}$ e glicemia de jejum $301 \mathrm{mg} / \mathrm{dL}$. Ao exame anatomopatológico da biópsia de lesão cutânea, evidenciam-se na derme superficial e média inúmeras células xantomatosas e células epiteliódes, em muitos momentos circundadas por acúmulo de lipídios de localização extracelular, corroborando para o diagnóstico de xantomas eruptivos.
Após confirmação da persistência de elevados níveis tensionais com outras aferições em nível ambulatorial, foi realizado o diagnóstico de síndrome plurimetabólica: hipertensão arterial sistêmica (HAS), DM tipo II, obesidade e dislipidemia, sendo prescritas drogas antidiabéticas orais, agentes hipolipemiantes, drogas anti-hipertensivas, associados a orientações sobre mudanças no estilo de vida. Discussão: A síndrome plurimetabólica caracteriza-se por cinco critérios, todos estes presentes no caso relatado: colesterol HDL $<40 \mathrm{mg} / \mathrm{dL}$, triglicerídeos ? $150 \mathrm{mg} /$ $\mathrm{dL}$, circunferência abdominal $>102 \mathrm{~cm}, \mathrm{DM}$ tipo II e HAS. Este distúrbio conferiu ao paciente um alto risco cardiovascular além de um aumentado risco de pancreatite aguda devido às altas taxas de triglicerídeos. Os xantomas eruptivos participaram como únicos sintomas queixados pelo paciente, além de nortearem a investigação etiológica do distúrbio metabólico adjacente. $\mathrm{O}$ diagnóstico precoce e preciso apresenta grande influência no tratamento e na redução da morbimortalidade causada tanto pela síndrome plurimetabólica como pela hipertrigliceridemia isolada.

\section{Referência:}

Coelho, G.; Rocha, P.L.; Weinert, L.S.;. Síndrome Plurimetabólica Expressa Como Xantomas Eruptivos: A Importância Da Dermatologia No Diagnóstico De Doenças Sistêmicas.. In: II Congresso Brasileiro de Medicina Hospitalar - II CBMH [= Blucher Medical Proceedings, vol.1, num.5] São Paulo: Editora Blucher, 2014. p.53

DOI 10.5151/medpro-II-cbmh-048 